\title{
A Escola Estadual Quilombola José Mariano Bento e sua contribuição na preservação dos fazeres e saberes dos habitantes do Território Quilombola Vão
}

\author{
La escuela estatal de Quilombola José Mariano Bento y su contribución a \\ la preservación de las acciones y el conocimiento de los habitantes del \\ territorio de Quilombola.
}

The Quilombola State School José Mariano Bento and its contribution to the preservation of the doings and knowledge of the inhabitants of the Quilombola Territory

\author{
Madalena Santana de Sales ${ }^{1}$ \\ João Severino Filho ${ }^{2}$
}

\begin{abstract}
Resumo
Este artigo é um recorte da pesquisa do mestrado em Ensino de Ciências e Matemática do Programa de PósGraduação da UNEMAT-Campus de Barra de Bugres-MT, uma pesquisa qualitativa de caráter etnográfico, intitulada Os fazeres e os saberes etnomatemáticos praticados pelos habitantes do Território Quilombola Vão Grande. Nele discutimos a contribuição da Educação Escolar Quilombola na preservação dos saberes e dos fazeres, como a escola da comunidade dialoga saber local e saber escolar. Apresentamos um breve resumo da história da educação escolar no Território Quilombola Vão Grande, desde quando as aulas eram ministradas nas casas de um morador, até a atualidade. Percebemos que ela busca ofertar um ensino que valorize seus conhecimentos, sua vivência, sua cultura e sua ancestralidade negra.
\end{abstract}

Palavras-chave: Educação quilombola. Conhecimentos tradicionais. Saber local.

\section{Resumen}

Este artículo es un recorte de la investigación de la Maestría en Ciencias y Matemáticas del Programa de Posgrado de la UNEMAT-Campus de Barra de Bugres-MT, una investigación cualitativa de carácter etnográfico, titulada Los hechos y conocimientos etnomatemáticos practicados por los habitantes del Territorio Quilombola Vão Grande. En él se discute la contribución de la Educación Escolar Quilombola en la preservación del conocimiento y el hacer, cómo la escuela de la comunidad dialoga el conocimiento local y el conocimiento escolar. Presentamos un breve resumen de la historia de la educación escolar en el Território Quilombola Vão Grande, desde que se impartieron las clases en la casa de un residente hasta la actualidad. Nos damos cuenta de que busca ofrecer una enseñanza que valore su conocimiento, su experiencia, su cultura y su ascendencia negra.

Palabras clave: Educación quilombola. Conocimiento tradicional. Conocimiento local.

\footnotetext{
1 Mestra em Ensino de Ciências e Matemática pelo Programa de Pós-Graduação Stricto Sensu em Ensino de Ciências e Matemática - PPGECM, Universidade do Estado de Mato Grosso - UNEMAT, Campus Universitário Deputado Renê Barbour - Barra do Bugres - MT. E-mail: madalena74@ @otmail.com

2 Professor do Departamento de Matemática e do Programa de Pós-Graduação Stricto Sensu em Ensino de Ciências e Matemática - PPGECM, Universidade do Estado de Mato Grosso - UNEMAT, Campus Universitário Deputado Renê Barbour - Barra do Bugres - MT. E-mail: joaofilho@ unemat.br
} 


\begin{abstract}
This article is a cutout of the research of the Master in Science and Mathematics Teaching of the Post-Graduate Program of the UNEMAT-Campus of Barra de Bugres-MT, a qualitative research of ethnographic character, entitled The ethnomathematical doings and knowledges practiced by the inhabitants of the Quilombola Vão Grande Territory. In it, we discuss the contribution of the Quilombola School Education in the preservation of knowledge and doings, how the community school dialogues local knowledge and school knowledge. We present a brief summary of the history of school education in the Território Quilombola Vão Grande, from when classes were held in a resident's home to the present day. We realize that it seeks to offer a teaching that values its knowledge, its experience, its culture and its black ancestry.
\end{abstract}

Keywords: Quilombola education. Traditional knowledge. Local knowledge.

\title{
1. Introdução
}

Este texto apresenta um recorte da pesquisa qualitativa de cunho etnográfico "Fazeres e Saberes etnomatemáticos dos moradores do Território Quilombola Vão Grande”, apresentada ao Programa de Pós-Graduação Stricto Sensu em Ensino de Ciências e Matemática da Universidade do Estado de Mato Grosso - Campus de Barra do Bugres. No qual apresentamos um breve histórico da educação escolar no Território Quilombola Vão Grande, abordando desde quando as aulas aconteciam em um cômodo da casa, ministrada por um dos moradores, a construção das primeiras escolas, até chegada dos professores até a situação atual.

Na seção “dialogando sabe local e saber escolar”, discutimos como se dá a relação entre escola e comunidade, qual a sua contribuição na preservação dos saberes e fazeres, os trabalhos desenvolvidos pelos professores em cada área do conhecimento e nas disciplinas que compõem a "Ciências e Saberes Quilombolas".

O Território Quilombola Vão Grande localiza-se a $75 \mathrm{~km}$ da sede do município de Barra do Bugres - MT, no Complexo da Serra das Araras, sendo constituído de cinco comunidades: Baixio, Camarinha, Morro Redondo e Retiro pertencem a Barra do Bugres e Vaca morta pertencente ao município de Porto Estrela - MT.

Segundo os mais velhos, seus antepassados habitavam a região há mais de 200 anos. Algumas famílias ali chegaram, fixaram moradias e se casaram entre si, as quais fundaram novas comunidades. Isso explica a relação de parentesco.

O território está organizado socialmente em associações de moradores. Cada comunidade possui a sua, com regimentos próprios. Essas quais lutam pelo reconhecimento das comunidades ainda em andamento, assim como o resguardo da posse da terra na comunidade Morro Redondo e na Camarinha, buscando o reconhecimento e posteriormente a certificação como área de remanescente quilombola, pois sofrem com a insegurança, correndo o risco de perderem suas terras, terras de seus ancestrais. 
Os moradores ainda guardam os saberes e fazeres herdados de seus ancestrais. A cultura, a religiosidade, as festas de santos, as rezas, as ladainhas, os mitos, as lendas, o respeito aos mortos, os cumprimentos aos mais velhos e os saberes referentes ao plantio e a colheita, elementos que constituem especificidades das comunidades negras rurais.

\section{O percurso metodológico}

Resido no município de Barra do Bugres - MT e trabalho como professora na escola da comunidade há 11 anos, local onde permaneço de segunda-feira a sexta-feira e retorno para casa no final de semana. Dessa maneira, durante o período da tarde e, algumas vezes à noite realizei a pesquisa do mestrado.

As rodas de conversas são comuns entre os moradores, quando estão reunidos nas festas de Santo, na hora do descanso dos trabalhos na roça e nos momentos de descontração. Ao participar desses momentos, e eles sabendo que sou professora, as lembranças sobre a escola afloravam e faziam parte do assunto. Nesse contexto, surgiu a ideia de escrever sobre com a escola têm contribuído na preservação dos fazeres e dos saberes dos moradores.

Os sujeitos de pesquisa foram alguns dos moradores do Território Quilombola Vão Grande, as informações foram produzidas por meio de conversas gravadas e, algumas vezes registradas no caderno de campo. Os diálogos aconteciam nas casas com a presença da família, em grupo durante as festas de Santo e na escola com os professores. Por isso optamos pela pesquisa qualitativa na perspectiva da história oral.

Neste trabalho, buscamos sustentação em Godoy (1995) para compreender as relações sociais e culturais e todas as significações presentes em cada narrativa, relato e memórias evocadas. Nesse sentido, a autora discorre que a pesquisa qualitativa como metodologia nos permite alcançar os objetivos traçados.

\footnotetext{
Ainda quando a nossa preocupação for a compreensão da teia de relações sociais e culturais que se estabelecem no interior das organizações, o trabalho qualitativo pode oferecer interessantes e relevantes dados. Nesse sentido, a opção pela metodologia qualitativa se faz após a definição do problema e do estabelecimento dos objetivos da pesquisa que se quer realizar (GODOY, 1995, p. 63).
}

Ao relembrar fatos que marcaram suas vidas, seja na infância ao frequentar a escola como aluno ou na idade adulta como professor, seus semblantes, seus sorrisos mostram a importância dessa fase vivenciada por eles. É comum durante as conversas apontarem para a serra, a casa de algum morador e algum trecho da estrada onde aconteceram episódios que marcantes. Delgado (2003) pontua que esses aspectos são singularidades da história oral. 
Por ser uma experiência através da qual se compartilha o registro das lembranças, transforma a narrativa em processo compartilhado que inclui em si as seguintes dimensões: estímulo ao narrar, ato de contar e relembrar e disponibilidade para escutar. Fala, escuta e troca de olhares compõem a dinâmica desse processo único e essencial à vida humana, pois não se vive em plenitude sem a possibilidade escutar, de contar histórias e de se apreender sob a forma de conhecimento, ou melhor, de sabedoria, o conteúdo narrado (DELGADO, 2003, p. 23).

O Território Quilombola Vão Grande é carregado de memórias, vivências, cultura, saberes e fazeres ancestrais, que nos instiga a pesquisar, conhecer, escutar e deixar a imaginação viajar a cada nova história contada.

\section{Breve histórico da educação escolar no Território Quilombola Vão Grande}

A história da educação escolar no Território Quilombola Vão Grande tem seu início com as aulas ministradas nas casas, em um dos cômodos cedido pelo morador, alguns alunos precisavam se deslocar mais de $10 \mathrm{~km}$ a pé por entre as serras, sujeitos aos perigos que nela pudessem encontrar. $\mathrm{O}$ professor era um membro da comunidade que dominava a leitura, a escrita e alguns cálculos básicos. São memórias do Sr. Benedito Osvaldo.

O Sr. Benedito Osvaldo, morador da comunidade Baixio, hoje com 73 anos foi um dos professores na época. Ele relata que estudou até a $3^{\text {a }}$ série, mas que não estudava o ano letivo completo, apenas alguns meses por ano, mas que aprendeu ler e escrever e fazer cálculos.

As dificuldades enfrentadas nesse período foram muitas, como nos explica o $\mathrm{Sr}$. Benedito Osvaldo. Ele ministrava aulas de manhã para os alunos da Comunidade Baixio, Morro Redondo e Camarinha que pertenciam ao município de Alto Paraguai/MT, à tarde para os alunos da Comunidade Vaca Morta e Retiro que se localiza do outro lado do Rio Jauquara e pertenciam a Barra do Bugres/MT. No período chuvoso, ele relembra que precisava atravessar o rio com os alunos de canoa, para diminuir a quantidade de vezes que faria a travessia, pois a capacidade de canoa não era suficiente para todos, ele colocava os alunos e puxava.

\footnotetext{
Eu atravessava o rio com seis alunos na canoa, eu colocava as crianças e puxava, para atravessar mais ligeiro, porque se eu entrasse na canoa tinha que fazer o percurso mais vezes, tinha que dar três, quatro viagem (Sr. Benedito Osvaldo, morador da Comunidade Baixio. Junho de 2019).
}

Ele nos conta que, muitas vezes, ficava vários meses sem pagamento, precisava se deslocar até Alto Paraguai para receber seu pagamento, em algumas ocasiões, precisou ficar até quatro dias na cidade esperando, pois os gestores da época alegavam que não tinham dinheiro. 
Um dos episódios que marcou o Sr. Osvaldo quando atuava como docente foi quando voltava de uma das incursões ao município de Alto Paraguai para receber seu pagamento e buscar materiais pedagógicos. O percurso da MT 246 até o Território Quilombola era feito a pé. Para se ter uma ideia das dificuldades enfrentadas nesse período, quando o senhor Benedito Osvaldo fala que fazia o trajeto a pé, da MT 246 até chegar à sua casa são aproximadamente $45 \mathrm{~km}$, percurso feito por ele, carregando nas costas seus pertences, alimentos e os materiais pedagógicos fornecidos pela secretaria de educação do município.

Eu fui, porque nesse tempo a gente tinha que ir até com rede pra dormir, porque não tinha onde dormir, daí eu levei uma bolsa com roupa e a rede e de lá pra cá eu fiz compra de mantimentos e, ainda trouxe livro, caderno, lápis, caneta e borracha, uma caixa que dava mais ou menos $7 \mathrm{~kg}$ ou $8 \mathrm{~kg}$. O saco com os mantimentos pra cá, a bolsa aqui e a caixa na cabeça, saí de lá oito horas da manhã e cheguei oito horas da noite [...], noutro dia acordei com a cabeça inchada de carregar a caixa, não tinha costume de carregar nada na cabeça, vim a pé do estrada onde o ônibus parou até aqui (Sr. Benedito Osvaldo, morador da Comunidade Baixio. Junho de 2019).

A primeira escola construída foi na Comunidade Retiro, como nos conta o Sr. Maximiano, que o Sr. Leopoldino com a ajuda do prefeito de Barra do Bugres na época construiu a escola e levou uma professora para ministrar aulas, porém ela não morava na comunidade e precisava subir e descer a serra para chegar à escola e, com o passar do tempo e as dificuldades enfrentadas por ela, abandonou as aulas. Ele nos explica também que suas irmãs e irmãos mais velhos estudaram, mas ele, devido ser pequeno ainda e para chegar à escola era preciso atravessar o rio Jauquara e por isso não frequentou a escola nesse período.

\footnotetext{
Quando eu era criança, minhas irmãs foram a escola, o Leopoldino buscou professora, conversou com o prefeito na Barra, ele trouxe material e fez a escola, então veio uma professora chamada Arcelina, mas nessa época eu não estudava, eu era bem pequeno, tinha que atravessar o Jauquara, as minhas irmãs mais velhas, todas as pessoas mais velhas de certa idade aprenderam a assinar o nome, com essa professora, com o passar do tempo, comecei a ir para a escola, mas logo a professora foi embora e não voltou mais, mas também, tinha que subir serra atravessar o Jauquara (Sr. Maximiano, morador da comunidade Baixio. Abril de 2019).
}

Na comunidade Vaca Morta, há uma escola, hoje desativada que leva o nome do Sr. Leopoldino, pois as aulas foram nucleadas e os alunos transferidos em 2018 para a escola José Mariano Bento.

O Sr. José Ambrósio também estudou na escola criada pelo Sr. Leopoldino, a distância que ele percorria a pé juntamente com seu pai, atravessando a mata e o rio Jauquara é de aproximadamente $10 \mathrm{~km}$, reclama que só frequentava as aulas no período da seca, pois durante as chuvas o volume de água do rio é grande e tornava a travessia perigosa. 
Pra ir à aula, eu atravessava a mata do Jauquara, lá na passagem do retiro. Eles me levavam lá, mas só quando era tempo de seca, no tempo da água não podia ir, pois Jauquara ficava cheio demais, eu não aprendi nada, só um pouquinho (Sr. José Ambrósio morador da Comunidade Morro Redondo. Abril de 2019).

Algo que marcou o Sr. José Ambrósio foi o método de ensino utilizado pelo professor, é perceptível nas conversas que sempre que ele toca no assunto da escola, o que vem à sua memória são os castigos físicos.

O professor era o finado Leopoldino, era barbudo, feio demais e tinha um filho chamado Godofredo. Pegava ele pela orelha e passava perto de nós com ele pendurado, meu Deus do céu, ficávamos com muito medo. O professor tinha uma palmatória furada, qualquer coisa que a gente fazia ele vinha de lá, ah, medo triste, daí com o passar do tempo parei de ir à escola, mas nesse tempo todas as coisas eram tranquilas, eu não aprendi nada mesmo, mas era desse jeito, nesse tempo que nós vivíamos (Sr. José Ambrósio morador da Comunidade Morro Redondo. Abril de 2019).

O senhor Maximiano, mesmo criança nesse período, se lembra de que as aulas na Comunidade Baixio, como nas outras comunidades do Território acontecia nas casas "o prefeito de Alto Paraguai começou a criar umas escolas nas casas, aqui no Baixo foi da residência do Antônio e do compadre Manoel".

Para esclarecer, quando o senhor Maximiano fala que era o prefeito de Alto Paraguai, o Território Quilombola Vão Grande, assim como o Distrito de Currupira pertenciam ao município de Alto Paraguai, mas após reinvindicações dos moradores em 1999, aconteceu o plebiscito e os moradores do Vão Grande, que nesse momento não era reconhecido como área de remanescentes de quilombolas e do Distrito de Currupira, votaram e optaram que ambos fossem incorporados à cidade de Barra do Bugres/MT, pois eles alegavam que tudo o que precisavam era feito em Barra do Bugres, desde atendimento médico e compras de mercadorias.

Após esse período em que aulas eram ministradas nas casas, a prefeitura de Alto Paraguai construiu as escolas feitas de madeira nas comunidades Morro Redondo, Camarinha, Baixio as comunidades Vaca Morta e Retiro pertencentes a Barra do Bugres compartilhavam a mesma escola. Em algumas comunidades, a escola era também a moradia das professoras e professores. Esses profissionais, além de ministrar aulas, preparavam o lanche e limpavam a escola, não havia água encanada, era preciso buscar no rio e levar os utensílios para lavar no lá.

Nesse momento da história, as escolas atendiam somente até a $4^{\mathrm{a}}$ série, o $5^{\mathrm{o}}$ ano atualmente. Após o término dessa etapa escolar, alguns mudavam para cidade para morar com 
parentes e estudar, outros paravam, pois não tinham opção. Isso perdurou até 2002, quando as professoras Dinalva, Lucimara e Maria Helena que já atuavam nas escolas, uma em cada Comunidade, juntamente com os moradores conseguiram a abertura de salas anexas de escolas municipais. Então já era possível terminar o ensino fundamental, porém mais uma vez alguns alunos e pais sonhavam com o ensino médio. Novamente entram em cena a Comunidade e as professoras que também eram moradoras para trazer essa modalidade de ensino, e assim as salas anexas são da E. E. Sabino Ferreira Maia, ou seja, em um mesmo espaço três escolas diferentes, a escola rural São José do Baixio, salas anexas da escola municipal Guiomar de Campos Miranda, atendendo os alunos do $6^{\circ}$ ao $9^{\circ}$ ano e o ensino médio da escola Sabino Ferreira Maia.

A partir de 2009, começo a fazer parte dessa realidade, pois sou contratada com professora de matemática para ministrar aulas no ensino médio nas salas anexas da Escola Sabino Ferreira Maia. Nessa ocasião, os encaminhamentos para estadualizar e nuclear as escolas estão avançados.

A escola possuía duas salas de aula, uma secretaria, dois banheiros e uma cozinha, o número de alunos era aproximadamente 200. Com a falta de espaço para abrigar as salas de aula, os moradores construíram barracões cobertos de palha de babaçu, tanto alunos como professores estavam sujeitos às intempéries da natureza, chuva, vento, frio e poeira.

Em 2010, após muitas reivindicações e luta da Comunidade, a SEDUC/MT criou em fevereiro de 2010, pelo Decreto de nº 2378 de 22 de fevereiro de 2010 a Escola Estadual José Mariano Bento.

Os sonhos dos moradores estavam se concretizando, em 2011 iniciaram-se as obras da escola, e com isso a esperança de que os tempos difíceis estavam terminando, porém com um prazo de 12 meses para concluir, a obra se arrastou por 4 anos. Muitos foram os problemas com a construção, a obra foi paralisada, o motivo alegado foi falência da empreiteira que ganhou a licitação. Nesse intervalo de tempo, os barracões continuaram sendo as salas de aulas.

No ano de 2014, a gestão, funcionários, professores e comunidade tomaram a decisão de ocupar a escola, mais precisamente as salas de aula durante o dia, pois os barracões apresentavam risco, no período chuvoso, as aulas precisavam ser interrompidas, porque a água da chuva molhava os alunos e seus pertences. Eles precisavam caminhar cerca de $200 \mathrm{~m}$ para se abrigar no prédio de madeira, amontoados em um pequeno espaço.

Os desafios enfrentados foram muitos, a SEDUC/MT, após termo de responsabilidade assinado pela gestão, liberou as salas de aula inacabadas, sem energia elétrica, sem parte 
hidráulica concluída, a alimentação era preparada na escola de madeira, pois a cozinha estava inacabada. Para se alimentarem e usar os sanitários os alunos tinham que se deslocar até a velha escola.

Passados dois anos, nova licitação e dessa vez pensamos que seria concluída, mas os escândalos envolvendo a SEDUC/MT e a empreiteira responsável fez com que as obras fossem paralisadas novamente, os problemas se acumularam. Somente em 2017, após nova licitação a escola foi concluída.

Faço aqui alguns apontamentos por ocasião de minha chegada à escola do Vão Grande, a nova realidade com a qual me deparei é um tanto desafiadora e causou-me até certo receio, mesmo praticamente nascida em Barra do Bugres, não tinha conhecimento de que havia um Território Quilombola no município, fato que só tomei conhecimento quando cheguei à escola.

As discussões sobre educação quilombola ainda para nós professores e professoras que vínhamos da cidade, mas não somente para nós, até mesmo para as professoras que moravam na comunidade, era tudo muito novo, a academia não nos preparou para essa realidade. Enfim, nesse mesmo ano, iniciaram-se as formações promovidas pelo CEFAPRO (Centro de Formação e Atualização dos Profissionais da Educação Básica de Mato Grosso), mas as dúvidas, as incertezas sobre como fazer, o que fazer permeava nossos pensamentos.

Gomes (2004) ressalta que existem outros fatores que devem ser considerados, no que diz respeito à formação de professores no que tange à diversidade, neste caso a educação escolar quilombola.

\begin{abstract}
Mas apenas investir numa melhor formação não é o suficiente. A formação de professores/ras, sobretudo a que visa a diversidade, deveria considerar outras questões, tais como: como os/as professores/ras se formam no cotidiano escolar? Atualmente, quais são as principais necessidades formadoras dos/das docentes? Que outros espaços formadores interferem na sua competência profissional e pedagógica? Que temas os/as professores/ras gostariam de discutir e de debater no seu percurso de formação e no dia-a-dia da sala de aula? E que temáticas sociais e culturais são omitidas, não são discutidas ou simplesmente não são consideradas importantes para a sua formação profissional e para o processo educacional dos seus alunos? Será que a questão racial está incluída nessas temáticas omitidas ou silenciadas? (GOMES, 2004, p. 169).
\end{abstract}

A partir da estadualização da escola, em 2010, a gestão, por meio da assessoria pedagógica, recebeu um comunicado que novas disciplinas integrariam o currículo. Devido às especificidades da educação escolar quilombola, as Ciências e Saberes Quilombolas compostas por três disciplinas: prática em tecnologia social, prática em cultura e artesanato quilombola e prática em técnicas agrícolas quilombola e as demais disciplinas também têm 
que trabalhar de acordo a realidade local considerando suas vivências, seus saberes e fazeres. O que fazer? Como fazer? Eram nossos questionamentos, pois não tivemos nenhuma formação seja inicial ou continuada sobre o assunto.

De posse do matriz curricular, com as novas disciplinas fornecidas pela SEDUC, através da superintendência de diversidade, iniciamos os trabalhos com o que pensávamos ser, mas nossas angustias, só aumentavam e, assim, após discussões na escola, a gestão solicitou da superintendência que um técnico fosse até a escola e nos auxiliasse nesse processo.

Nesse mesmo ano, a SEDUC/MT firmou parcerias com a Universidade Federal do Estado de Mato Grosso - UFMT e o Núcleo de Estudos e Pesquisas sobre Relações Raciais e Educação, para ofertar os cursos de formação e aperfeiçoamento para as escolas quilombolas de Mato Grosso.

O curso de extensão Formação de Professores das Comunidades Remanescentes de Quilombo ofertado tinha carga horária de 200 h, dividido em 5 módulo. Cada escola se organizava de maneira que a cada ano um grupo de professores pudesse participar. Compareceram professores das cidades de Barra do Bugres, Vila Bela da Santíssima Trindade, Nossa Senhora do Livramento, Chapada dos Guimarães e Poconé.

As temáticas dos módulos foram: educação anti-racista, didática e a intervenção pedagógica, escravidão e resistência, educação e relações étnico-raciais e orientação de projetos.

Além dos cursos de formação, os professores da Escola Quilombola José Mariano Bento participam desde 2010 do Semiedu (Seminário de Educação) promovido pela UFMT e da Jornada Desigualdades Racial na Educação Brasileira, evento realizado pelo NEPRE, que acontece paralelo ao Semiedu, apresentando relatos de experiências em educação escolar quilombola.

Ainda em 2016, foi aprovado o PROINQ - Programa de inclusão de estudantes quilombola, com primeiro vestibular para 2017, o PROINQ, é um Programa aprovado pela Resolução CONSEPE $n^{\circ}$ 101, de 26 de setembro de 2016 e Resolução CONSEPE nº 32, de 06 março de 2017. O programa garante 100 vagas por ano e o acesso de alunos quilombolas em todos os cursos ofertados pela UFMT, com vestibular específico e as provas aplicadas nas Comunidades Quilombolas. A aprovação do programa deu-se após muitas lutas da comunidade acadêmica, dos quilombolas e de instituições parceiras, uma ação afirmativa de reparação a tantos anos de desigualdades educacionais vivenciados pelos quilombolas. A responsável pelo PROINQ é a Pró-Reitoria de Assistência estudantil a PRAE. 
De acordo com Silva (2004) o sistema de cotas é uma maneira de reparar os séculos de invisibilidade e silenciamento que a população negra vivenciou e vivencia.

A distorção a corrigir, com a reserva de vagas, diz respeito à desvantagem acarretada pelo impacto de experiências culturais e educacionais privilegiadas que empobrecidos e negros não têm em relação a pertencentes a classes abastadas, na sua maioria brancos, ao concorrer por vagas no ensino superior público (SILVA, 2004, p. 2).

Aos alunos aprovados e matriculados é disponibilizada bolsa permanência que os auxiliará nos gastos com moradia, alimentação e deslocamento, e também apoio emocional feito por psicólogos para ajudá-los nesse momento de adaptação à nova realidade longe do convívio familiar. Em 2018, o vestibular foi suspenso devido à diminuição no número das bolsas permanência, isso tem influência direta sobre os que precisam se manter longe de suas residências para estudar, pois os pais não possuem condições financeiras para mantê-los em outra cidade.

Em 2017, o Conselho Estadual realizou audiências públicas nas comunidades quilombola com o título: A escola que temos e a escola que queremos, para ouvir os anseios e as reivindicações dos moradores sobre as escolas dos quilombos. Nessa ocasião, as discussões foram as condições de acesso à escola e o término da obra.

Em 2019, solicitou-se que se fizesse o levantamento da quantidade de quilombolas para ingressar na universidade pelo PROINQ e também o número de alunos que prestaram o ENEM, depois de cumpridas as exigências, estaria programado o lançamento do edital para o segundo semestre desse mesmo ano, porém isso não aconteceu.

Se por um lado a educação escolar quilombola avançou nos últimos tempos, por outro os desafios ainda são grandes. A precariedade das estradas e o transporte escolar insuficiente, que não supre suas necessidades, são alguns aspectos que fragilizam a educação escolar no Território Quilombola Vão Grande.

Devido a distância entre as cinco comunidades e somente um ônibus para fazer o transporte dos alunos até a escola, eles permanecem cerca de três horas dentro do ônibus, empoeirados e submetidos à temperatura elevada.

Ao poder público, compete oferecer condições dignas para que os alunos cheguem até a escola, desconsidera todas as situações já relatadas pela comunidade escolar e moradores. A manutenção das estradas só é feita após muitas reivindicações da comunidade, sendo uma das principais ações para minimizar o sofrimento dos alunos. 
O Território Quilombola Vão Grande é cortado pelo Rio Jauquara, durante o período chuvoso seu volume de água é grande, isso faz com que a ponte que duas comunidades, a qual é usada na travessia, tanto para ir para à escola quanto para ir à cidade, seja carregada, o que aumenta os problemas.

Em 2014, a ponte foi levada pela água do rio e na ocasião construiu-se uma passarela (Figura 1) suspensa em cabo de aço até construção da nova ponte, porém até o momento isso não aconteceu, ou seja, passaram-se seis anos de descaso. Nesse período de tempo, a passarela também, algumas vezes, é levada pelas águas. Quando isso ocorre os alunos atravessam o rio de barco, aumentando a preocupação dos pais com a segurança de seus filhos.

O aluno quilombola enfrenta uma luta diária para chegar à escola durante todo o ano letivo, sua rotina escolar diária é de aproximadamente nove horas entre sua saída e retorno para casa.
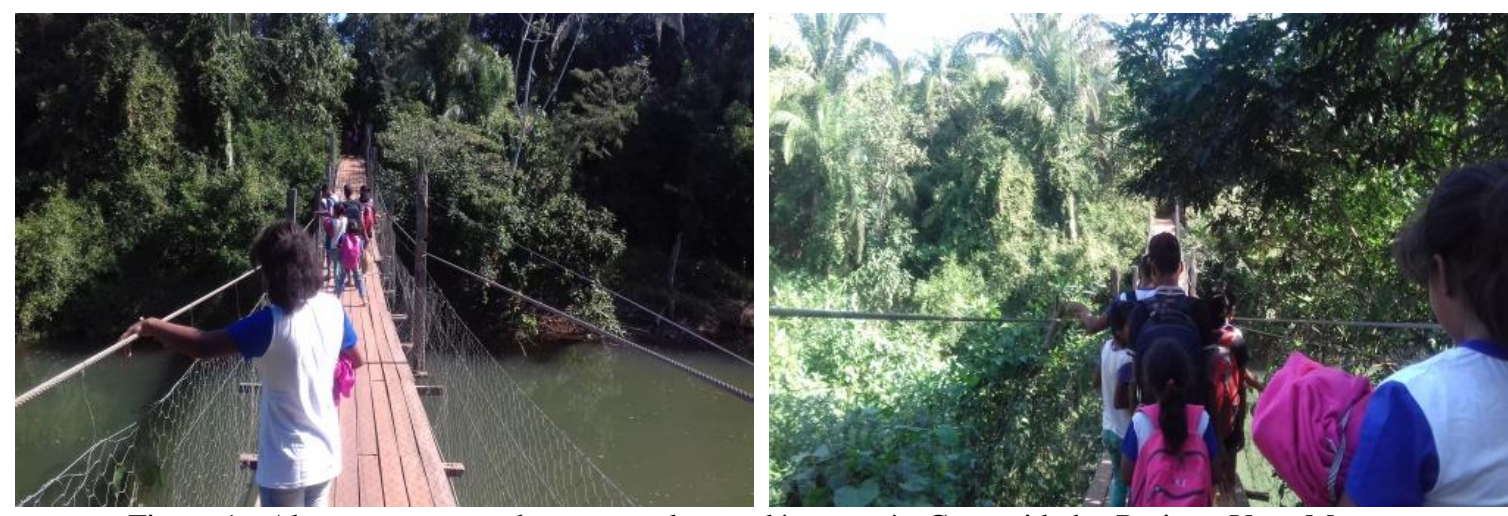

Figura 1 - Alunos atravessando a passarela que dá acesso às Comunidades Retiro e Vaca Morta. Fonte: Pela autora (março/2019).

Quando o aluno chega à escola está cansado e empoeirado, depois de um percurso de 2 $\mathrm{h}$ à $2 \mathrm{~h}$ e 30 min e ainda terá pela frente $4 \mathrm{~h}$ de aula. Crianças e adolescentes enfrentam esses desafios. Como esperar que eles tenham o mesmo desempenho dos alunos com condições que favorecem o aprendizado. É preciso equidade, que se tenham oportunidades iguais.

As dificuldades, os enfrentamentos e os desafios são diversos, desde insuficiência do transporte escolar até a falta de acesso a pesquisa, pois a escola não possui laboratório de informática, nem mesmo internet para acesso dos professores e alunos, o pacote de internet é pago pelos profissionais da educação da unidade escolar. A biblioteca não possui acervo para pesquisas, ela é composta em sua maioria por livros didáticos, questões que fragilizam e interferem no aprendizado. 


\title{
4 Dialogando saber local e saber escolar
}

Nas Comunidades Quilombolas saber local e saber escolar complementam-se, considerando o conhecimento adquirido de suas vivências, sua ancestralidade negra, seus valores culturais e seus saberes e fazeres, apresentando subsídios para que o aluno quilombola compreenda o seu lugar no mundo.

Dias (2017) nos diz que não há separação entre a educação nascida no seio das Comunidades Quilombolas e a educação formal.

\begin{abstract}
Compreende-se dessa forma que essas duas formas de educação, uma protagonizada pelos moradores quilombolas do seu cotidiano de vida e outra institucionalizada no espaço escolar, se tornaram indissociáveis no processo de formação do estudante quilombola, onde haveria a necessidade de entender o mundo social a partir de sua história, sua memória, crenças, de seu cotidiano de vida nas práticas de agricultura quilombola e nas práticas das manifestações religiosas e culturais das comunidades quilombolas (DIAS, 2017, p. 69).
\end{abstract}

As Diretrizes Curriculares Nacionais para Educação Escolar Quilombola (2013) alicerçada na Convenção 169, que dispõe sobre os Povos indígenas e Tribais e em documentos legais que as escolas quilombolas ou escolas que recebam alunos provenientes de Territórios Quilombolas considerem suas especificidades culturais e seus modos de produção de conhecimento e seus métodos de ensino e aprendizagem.

$\mathrm{O}$ aluno quilombola, desde pequeno, quando chega à escola traz os conhecimentos adquiridos no seio familiar, pois muitas vezes, ele acompanha os pais na roça, nas festas de Santo, nas rezas e nas mais diversas atividades desenvolvidas no seu cotidiano e cabe à escola valorizar e contribuir com a autoafirmação de sua identidade negra. Gomes (2004) fala sobre como se dá essa difusão de conhecimentos nesse contexto cultural.

\footnotetext{
Entre os processos culturais construídos pelos homens e pelas mulheres na sua relação com o meio, com os semelhantes e com os diferentes, estão as múltiplas formas por meio das quais esses sujeitos se educam e transmitem essa educação para as futuras gerações. É por meio da educação que a cultura introjeta os sistemas de representações e as lógicas construídas na vida cotidiana, acumulados (e também transformados) por gerações e gerações (GOMES, 2004, p. 170).
}

Não há como separar a criança, o adolescente, o jovem e o adulto do aluno, os conhecimentos aplicados no plantio, nas construções das casas de barro e palha, na análise do clima, do solo e nos cuidados com água, elementos que constituem a sua essência. Isso porque, nas Comunidades Quilombolas, praticamente todas as ações são realizadas 
coletivamente e assim as pessoas de todas as idades estão envolvidas na realização das tarefas, ambientes socioeducativos que transmitem saberes e fazeres.

Para D’Ambrosio (2007) é a transmissão e difusão de conhecimentos que garante a continuidade desses povos.

Conhecimentos e comportamentos são compartilhados e compatibilizados, possibilitando a continuidade dessas sociedades. Esses conhecimentos e comportamentos são registrados, oral ou graficamente, e difundidos e passados de geração para geração. Nasce, assim, a história de grupos, de famílias, de tribos, de comunidades, de nações (D’AMBROSIO, 2007, p. 22).

Nesse contexto, a Educação Escolar Quilombola pensa em um currículo que valorize a ancestralidade negra, suas especificidades e seja inserido na educação básica, na formação inicial, na pós-graduação e nas formações continuadas de professores que trabalham em escolas quilombolas ou que atenda alunos quilombolas.

De acordo com Dias (2017):

\begin{abstract}
Espera-se, portanto, que as histórias de vida contadas sobre os processos de organização da festa de santo na comunidade [...] das práticas desenvolvidas nas comunidades, nas etapas dessas manifestações dos saberes que são produzidos nos fazeres das festas de santo, no feitio das casas e das roças, na educação transmitidas pelos mais experientes e nas formas de ensinar e aprender, sejam incluídos nos currículos, nas formações inicial e continuada dos professores quilombolas e que atuam em escolas quilombolas, nas disciplinas especificas criadas para diminuir a distância entre o fazer e saber da escola e o saber e fazer da comunidade, se tornando assim a parte complementar e diversificada do currículo escolar para escolas quilombolas (DIAS, 2017, p.70).
\end{abstract}

A discussão sobre o ensino ofertado na escola do quilombo que, partindo da vivência dos alunos, os projetos e pesquisa buscam contribuir com suas necessidades, seja de geração de renda, cultura, autoafirmação e na identidade quilombola. Moreira e Candau (2003) salientam que não existe educação que não esteja imersa na cultura de um povo.

Nesse contexto para Moreira e Candau (2003) a escola e a cultura se complementa.

A escola é, sem dúvida, uma instituição cultural. Portanto, as relações entre escola e cultura não podem ser concebidas como entre dois pólos independentes, mas sim como universos entrelaçados, como uma teia tecida no cotidiano e com fios e nós profundamente articulados (MOREIRA; CANDAU, 2003, p. 160).

A professora Dinalva leciona aproximadamente há vinte anos na comunidade, ela nos fala sobre os trabalhos desenvolvidos nas disciplinas que compõem as Ciências e Saberes Quilombola. 
A prática em cultura e artesanato do quilombo são trabalhadas os artesanatos e a cultura, todas as especificidades existentes no quilombo, na disciplina tecnologia social quilombola, são trabalhadas as tecnologias utilizadas no quilombo, usados antigamente pelos seus antepassados e que usam até hoje, que é o pilão, a viola de cocho, as construções das casas, vários tipos de artesanatos, as especificidades próprias do quilombo. As formas de plantio, a tecnologia própria na construção de equipamentos para serem usados na plantação, no uso no lar e na construção das moradias, envolve tudo isso. Além da gente ter os estudos na escola, saímos a campo para fazer entrevista com os mais velhos, para que eles possam demonstrar como e feito o plantio, a relação que tem entre o modo de plantio de hoje com o de antigamente, com a cultura deles, com a cultura local. Esses ensinamentos também são repassados de pais para filhos, porque só assim eles podem afirmar suas identidades, seus valores e saberes que atravessam o tempo (Professora Dinalva Araujo de Campos. Março de 2020).

As palavras de Castilho e Ferreira (2014) reforçam a fala da Professora Dinalva quando diz:

\begin{abstract}
A Educação Quilombola é aquela própria de um povo, diversa e vinculada a uma especificidade cultural. Embora com algumas semelhanças entre comunidades, em suas maneiras de estabelecer processos educativos, cada uma tem sua dinâmica influenciada pelas formas tradicionais de organização social. Na maioria destas comunidades, a socialização dos conhecimentos, das tradições, do "ser quilombola", se dá a partir da convivência e observação dos mais velhos, tendo a tradição oral como o mais importante meio de transmissão do conhecimento. (CASTILHO; FERREIRA, 2014 p. 14.)
\end{abstract}

Por exemplo, nas aulas de língua portuguesa, a produção de textos é de acordo com o cotidiano quilombola, associando à ação linguística sobre suas vivências, variedades linguísticas de outras regiões e da comunidade, a matemática presente na confecção e no desenho de máscaras africanas, a matemática presente nos jogos africanos, matemática e conscientização ambiental, medidas agrárias pelo método quilombolas e método escolar, o uso da estatística no levantamento populacional e socioeconômico do Território Quilombola Vão Grande e trabalhando interdisciplinarmente no projeto de beneficiamento da banana, produção de farinha de mandioca e reprodução de pratos da culinária quilombola, nas ciências com a produção de remédios com as ervas medicinais do quilombo, orientada pelos pais dos alunos, valorização da beleza negra, ensino da geografia sobre os aspectos locais, confecção de miniaturas de pilão e viola de cocho. Nesse sentido Souza, Nunes e Melo (2016) afirmam que.

Para viabilizar uma educação escolar nesses territórios, é preciso levar em consideração todas as questões que circundam o espaço da escola; torna-se imprescindível uma grande dose de compreensão e sensibilidade para que se perceba o quanto, nas comunidades quilombolas, a educação se realiza por intermédio da transmissão de valores que se unem por meio dos fios da memória recriando constantemente, territorialidades forjadas sob diferentes concepções do uso da terra, 
muitas vezes atreladas a sistemas simbólicos de crenças que redimensionam concepções de produção, consumo e vida (NUNES; MELO, 2016, p. 40).

A professora Marcia ministra aulas de português, artes e espanhol. Ela nos fala sobre os trabalhos desenvolvidos em suas disciplinas e enfatiza a importância de considerar os saberes e os fazeres dos moradores do Território Quilombola Vão Grande, seus conhecimentos adquiridos ao longo de sua vivência.

Eu trabalhei com memórias, ele tinha a finalidade de mostrar como era antigamente. Então trabalhamos com a história de antigamente e os objetos que nós conseguimos encontrar com eles da comunidade, valorizando as memórias deles. O gênero textual é mais o cotidiano, as receitas, os saberes das mulheres, como fazer os remédios, os manuais de instruções, usamos a casa deles, os saberes aplicados ao fazer a casa. Contos, memórias e lendas Esse foi muito importante, porque os alunos puderam entender o que é lenda e falar sobre as lendas contadas pelos mais velhos, foi um deles. Isso é importante, porque são saberes quilombolas de seus ancestrais, por isso que eu considero importante. E temos também o do linguajar, o dicionário regional. $\mathrm{Eu}$ acho isso significativo, falamos das variedades linguísticas e nisso, nós trabalhamos o dicionário da comunidade que valoriza também o linguajar deles [...] (Professora Marcia Rezende de Sousa. Fevereiro de 2020).

Os professores e a equipe gestora estão empenhados em trabalhar de maneira que contemple as especificidades da Educação Escolar Quilombola. É preciso considerar todo o conhecimento que o aluno traz quando chega à escola, suas vivências, suas memórias e seu modo de vida, trabalhando de forma que alie os saberes escolares e os saberes locais.

Para a professora Marcia Rezende, o cotidiano dos alunos e os conteúdos curriculares quando trabalhados juntos contribuem com o aprendizado.

Eu acho significativo, porque quando aluno percebe que tem presente o seu cotidiano nas aulas e nos conteúdos curriculares, porque, às vezes, você está explicando um conteúdo que eles não se interessam muito, mas quando eles percebem que é vivenciado no cotidiano deles, eles se animam mais, por isso é um recurso importante (Professora Marcia Rezende de Sousa. Fevereiro de 2020).

O professor Antonio Marcos leciona ciências, ciências da natureza e ciências e saberes quilombolas. Ele assim como os demais, trabalham na perspectiva da valorização dos saberes e fazeres da comunidade. Em suas aulas, tem desenvolvidos projetos como a fabricação de miniaturas de pilão e reprodução de remédios caseiros, utilizados pelos moradores no tratamento de algumas doenças. Ele nos descreve algumas das atividades desenvolvidas em suas disciplinas.

Na tecnologia social, trabalhamos com a confecção do pilão, para fortalecer a cultura local para que jovens percebam e continuem percebendo a importância da 
sua cultura e da comunidade [...] no sentido de fortalecer a cultura local. Saímos na comunidade, conversamos com as pessoas, como faziam o pilão. Elas falaram que fazem com a madeira da árvore chamada lixeira. É uma das melhores madeiras para fazer o pilão. E foi assim que a gente fez. Como nós não tínhamos madeira do diâmetro para fazer do tamanho normal para uso da casa, nós fizemos pequenos, de $20 \mathrm{~cm}$ e $30 \mathrm{~cm}$. Pegamos a madeira já seca, a árvore estava caída, nós fomos nas casas e eles mandaram pegar e fizemos os pilões. Eles falaram os processos, como é que faz. Eles cavam um pouquinho e daí colocam pra queimar onde vai fazer a cava, elas são queimadas. Até mesmo pra curar a madeira, eles falaram que é esse o processo, deixam vários dias queimando e eles vão cuidando (Professor Antonio Marcos Pereira da Silva. Fevereiro de 2020).

No trabalho sobre plantas medicinais, o professor Antonio Marcos realizou com os alunos do ensino médio e contou com a participação do Sr. Inácio, morador da comunidade Baixio, que os acompanhou até a mata para a colheita das ervas medicinais e dos pais os alunos no preparo de chás, tinturas, xaropes, pomadas e banhos. Após a coleta do material, fizeram o levantamento etnobotânico das plantas e o registro das receitas fornecidas pelos moradores.

Além dos trabalhos realizados nas disciplinas, os moradores são convidados para ministrar oficinas de confecção de apá, peneira, tapetes e redes. A escola entende que essa é uma maneira de preservar, difundir e valorizar o conhecimento. De acordo Gomes (2004)

Nesse sentido, quando pensamos a articulação entre educação, cultura e identidade negra, falamos de processos densos, movediços e plurais, construídos pelos sujeitos sociais no decorrer da história, nas relações sociais e culturais. Processos que estão imersos na articulação entre o individual e o social, entre o passado e o presente, entre a memória e a história (GOMES, 2004, p. 170).

Além de trabalhar as questões relacionadas à valorização dos saberes e fazeres e garantir a implantação da Lei 10.639/03, que trata do ensino de história de da cultura afrodescendente, a partir de 2015, a escola realiza a festa da consciência negra em parceria com a comunidade.

Ao pensar a festa, chegamos à conclusão de que deveria ser nos modos e maneiras das festas de Santo. A comunidade acatou a ideia e, desde então, a cada ano é realizada em uma comunidade. As atividades desenvolvidas nesse dia são a dança de São Gonçalo, a dança do Siriri, alunos e professores apresentam os trabalhos realizados na escola (Figura 2 e 3). 

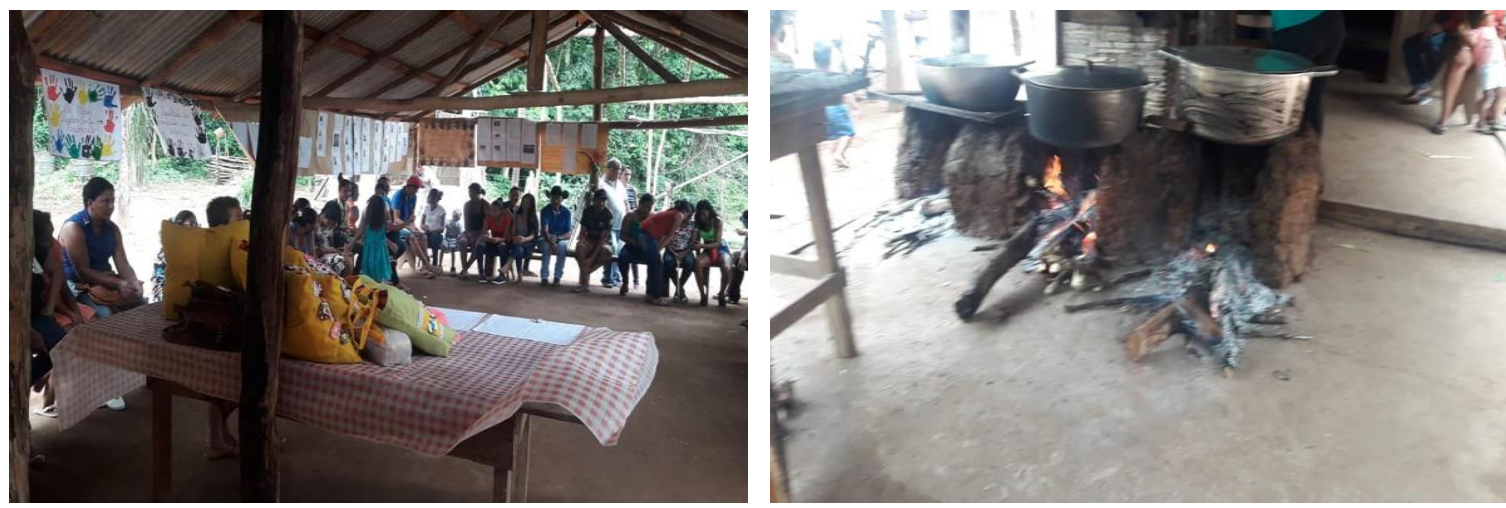

Figura 2 - a) Moradores, alunos e profissionais da educação da E. E. Q. José Mariano Bento. b) Preparo do almoço. Fonte: Acervo Maria Helena Tavares Dias.
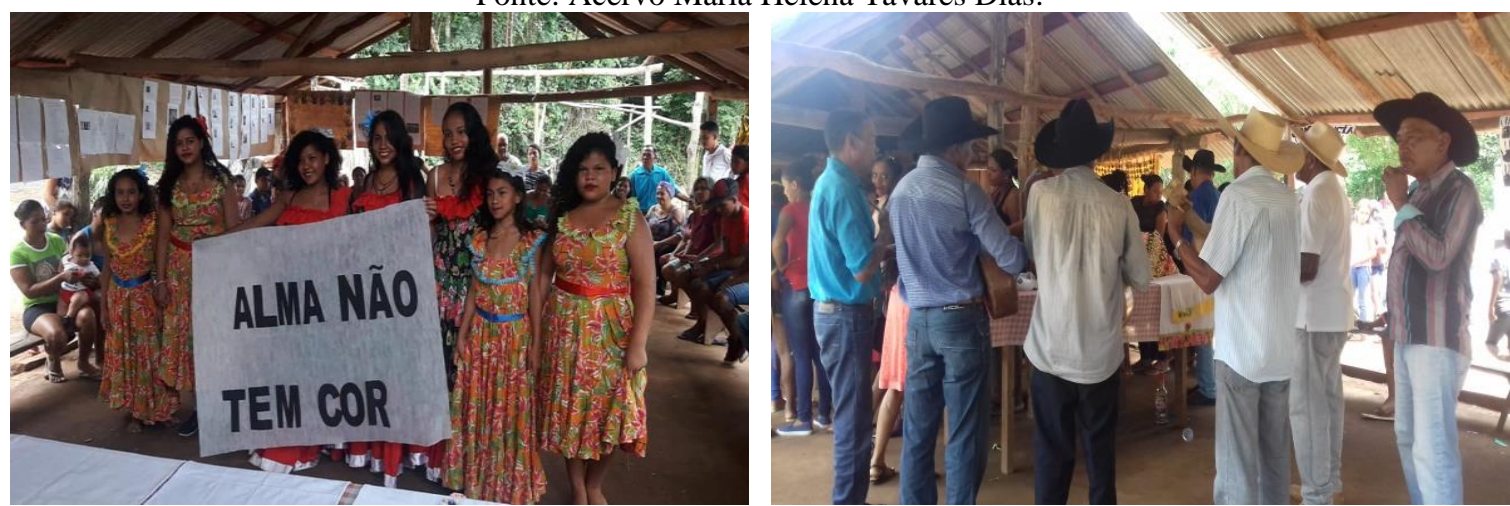

Figura 3 - a) Grupo de dança da E. E. Q. José Mariano Bento. b) b) Cantadores tocando logo após a dança de São Gonçalo.

Fonte: a) acervo Maria Helena Tavares Dias (2018). b) Pela autora (novembro de 2018).

Um fato nos chamou atenção na ocasião da realização da primeira festa da consciência negra. Foi a seguinte: ao final da festa, pensamos em deixar o local da próxima festa marcado, então reunimos os presentes para discutir o assunto. A primeira aconteceu na comunidade Baixio, alguém sugeriu que fosse na comunidade Camarinha, porém um dos mais velhos disse que não poderia, pois a Camarinha está no sentido contrário, como ele disse está à esquerda, e deve-se obedecer o sentido direita para a esquerda, considerando as ponderações do morador, ficou acordado que as festas seguiriam a seguinte ordem, Baixio, Vaca Morta, Retiro, Morro Redondo, Camarinha, escola e assim o ciclo continuará. O nosso objetivo é que isso seja incorporado às manifestações culturais locais. Nesse contexto, Dias (2017) pontua que.

A educação quilombola também apresenta estruturas de transmissão de saberes. A educação escolar quilombola não prescinde dos processos e das formas de transmissão de saberes ancestrais das comunidades quilombolas, preservados no cotidiano de vida dos moradores, nos modos de produção de conhecimento a partir de seu mundo e da sua cultura de dentro para fora, do que é palpável para o imaginado (DIAS, 2017, p. 72).

Saber tradicional e saber escolar uma como complemento da outra, uma baseada nos saberes e nos fazeres, na vivência e na ancestralidade e a outra formalizada na escola, 
fundamentais na formação dos alunos, partindo de sua realidade para chegar ao conhecimento de mundo. Nessa linha, Gerdes (2007, p. 160) salienta que "Numa educação que reconhece e aproveita a existência de muitas culturas abre-se o horizonte do aluno, enriquecendo-o com experiências doutros povos doutros tempos".

Na Educação Escolar Quilombola, nos últimos tempos houve avanços e retrocessos, vencidos desafios e propostos outros, mas ainda há muito a fazer para que seja o ideal e o necessário, que minimize os séculos de invisibilidade e silenciamento.

\section{Conclusões}

Em minha experiência como professora na escola da comunidade, percebi que não há como desconsiderar o saber tradicional, que o aluno traz quando chega à escola. Cabe à escola valorizar esses saberes, estabelecer relações com o saber escolar, pois, nos quilombos os diversos espaços socioeducativos são compartilhados por adultos e crianças, difundindo saberes ancestral.

A educação escolar quilombola preconiza que as escolas localizadas em Território Quilombola Vão Grande devem considerar essas especificidades, valorizar o saber local, mas também dando subsídios para que esse aluno possa transitar por outras culturas, outras realidades, para que ele, caso queira ir para outros lugares, tenha condições de se adaptar, seja no mercado de trabalho ou nos estudos.

A escola da comunidade busca através dos projetos desenvolvidos aliar os saberes tradicionais com os saberes escolares e contribuir com o desenvolvimento socioeconômico dos moradores. Ela tem cumprido o seu papel ou pelo menos está tentando cumpri-lo quando traz a comunidade até a escola para que ensine a professores e alunos suas técnicas na arte de confeccionar apás e peneiras de buriti ou bambu, tapetes, redes, miniatura de pilão e ensinar a dança do siriri e São Gonçalo, além de trabalhar nas disciplinas com temas que contribua com a autoafirmação do ser "quilombola", e a valorização e sua identidade negra.

Os dias santos da comunidade previstos no calendário letivo mostram o respeito que a escola tem com a cultura e a religiosidade do povo.

\section{Referências}

BRASIL. Conselho Nacional de Educação. Diretrizes Curriculares Nacionais para a Educação Escolar Quilombola na Educação Básica. Resolução CNE/CEB nº 8, de 20 de novembro de 2012. Brasília, Diário Oficial [da] República Federativa do Brasil, 21 de novembro de 2012, $45 \mathrm{p}$. 
D’ AMBROSIO, Ubiratan. Etnomatemática - elo entre as tradições e a modernidade. Coleção Tendências em Educação Matemática. $2^{a}$ edição. Editora Autêntica. Belo Horizonte - MG, 2007.

DELGADO, L. A. N. História oral e narrativa: tempo, memória e identidades. HISTÓRIA ORAL, 6, 2003, p. 9-25.

DIAS, M. H. T. Entre memórias e narrativas dos festeiros das festas de santo do território quilombola Vão Grande. Dissertação de mestrado. Programa de Pós-graduação em Educação do Instituto de Educação da UFMT. Cuiabá - MT, 2017.

FERREIRA, A. E; CASTILHO, S. D. Reflexões sobre a educação escolar quilombola. RP3 Revista de Pesquisas em Políticas Públicas. Edição: 03 Ago/2014. Disponível em: https://www.academia.edu/22036623/Reflex\%C3\%B5es_Sobre_a_Educa\%C3\%A7\%C3\%A3 o_Escolar_Quilombola. Acesso em: $17 \mathrm{de} \mathrm{fev.} 2020$

GERDES, P. Etnomatemática - Cultura, Matemática e Educação. Colectânea de Textos (1979-1991). Reedição. Mocambique. 2012.

GEERTZ, C. A Interpretação das Culturas. Editora LTC, Rio de Janeiro - RJ. 2008.

GODOY, A. S. Introdução à pesquisa qualitativa e suas possibilidades. RAE - Revista de Administração de Empresas, São Paulo, v. 35, n. 2, p. 57-63.1995.

GOMES, N. L. Educação, identidade negra e formação de professores/as: um olhar sobre o corpo negro e o cabelo crespo. Educação e Pesquisa, São Paulo, v. 29, n.1, p. 167-182. 2003.

MOREIRA, A. F. B. CANDAU, V. M. Educação escolar e cultura(s): construindo caminhos. Scielo, n. 23. 2003.

SILVA, P. B. G. Direitos humanos, negros e educação. In: Simpósio: Educação em Direitos Humanos, Igualdade e Diferenças. 2004. Brasília.

SOUZA, E. P.; NUNES, G. H. L; MELO, W. F. (Orgs). Memória, territorialidade e experiências de educação escolar quilombola. Ed. UFPel. Pelotas, 2016. 